\title{
The evaluation of ocular changes in prediabetic individuals
}

\section{ABSTRACT}

Background. Prediabetes is the major risk factor for type 2 diabetes, but the prediabetic state itself is also associated with classical macrovascular and microvascular complications. Studies indicate that other ocular abnormalities can develop during the stage of prediabetes; however, data on the occurrence of ocular changes are limited. The aim of our study was to evaluate ocular changes in prediabetic individuals. Material and methods. Sixty subjects (40 women, 20 men) aged 37-78, with impaired fasting glucose and/ /or impaired glucose tolerance, were enrolled in the study and compared with 30 volunteers (20 women, 10 men) without prediabetes, aged 39-75. Both groups of patients underwent a complete physical examination, biochemical tests and ophthalmic examination: visual acuity testing, colour vision and letter contrast sensitivity tests, anterior and posterior segment evaluation, intraocular pressure measurement, fundus photographs and optical coherence tomography. Prediabetic patients underwent examinations twice: on the $1^{\text {st }}$ visit and on the $2^{\text {nd }}$ visit after 9-month period.

Results. Ophthalmic examination revealed in prediabetic individuals as compared to healthy controls increased prevalence of cataract $(31.67 \%$ vs. $6.67 \%$; p < 0.05$)$, corneal surface disorders $(21.67 \%$ vs. $3.33 \%$; $\mathrm{p}<0.05)$, posterior vitreous detachments $(76.67 \%$ vs. $55 \%$; $p<0.05)$, arterial narrowing $(81.67 \%$ vs. $63.33 \%$;

Address for correspondence:

prof. dr hab. n. med. Paweł Piątkiewicz

ul. Kondratowicza 8, 03-242 Warszawa

e-mail: piatkiewicz@op.pl

Translation: lek. Małgorzata Kamińska

Clinical Diabetology 2017, 6, 1, 8-16

DOI: $10.5603 /$ DK.2017.0003

Received: 15.02.2017

Accepted: 27.03 .2017 $\mathrm{p}<0.05)$ and hypertension angiopathy $(70 \%$ vs. $36.67 \% ; p<0.05)$. There were also differences between prediabetic and control groups in prevalence rate of retinopathy (8.33\% vs. $3.33 \%$; NS) and acquired colour vision impairment $(8.33 \%$ vs. $0 \%$, NS). When compared visit 1 to visit 2, statistically significant differences were observed in fasting plasma glucose level (106.9 vs. $104.1 \mathrm{mg} / \mathrm{dL} ; \mathrm{p}<0.05)$ and HbA1c $(5.80 \%$ vs. $5.99 \%$; $p<0.05)$. There were no statistically significant differences in ocular changes; however, increased prevalence of retinopathy signs was noted during the examination after 9-month period ( $8.33 \%$ vs. $12.73 \%$; NS).

Conclusion. Prediabetic subjects present increased prevalence of ocular disorders as compared to healthy population. Results of this study indicate that prediabetic state is the independent risk factor of these complications; although, many patients with prediabetes have other features of metabolic syndrome. The regular ophthalmic monitoring seems to be essential at the stage of prediabetes in order to detect ocular abnormalities and identify individuals at risk of other diabetic complications. (Clin Diabetol 2017; 6, 1: 8-16)

Key words: impaired fasting glucose, impaired glucose tolerance, prediabetic complications, retinopathy, posterior vitreous detachment, colour vision, diabetic cataract

\section{Introduction}

The prediabetes, defined as impaired fasting glucose (IFG) and/or impaired glucose tolerance (IGT), is a disorder that, like diabetes, is characterised by a constantly increasing prevalence, both in Poland and in the world. According to the International Diabetes Federation, in 2015 there were 415 million people with diabetes in the world. It is estimated that 642 million people will suffer from diabetes in 2040. Today 318 
million people worldwide have prediabetes and by 2040 this figure will increase to 482 million [1].

Prediabetes is one of the main risk factors for type 2 diabetes. It is estimated that $5-10 \%$ of people with IFG and/or IGT will develop type 2 diabetes within a year. Prediabetes is also an independent risk factor for development of typical diabetes complications. Patients with prediabetes have a higher incidence of cardiovascular disease and microangiopathy: retinopathy, nephropathy and neuropathy [2-4]. Considering the convergent pathophysiological mechanisms of prediabetes and type 2 diabetes, it can be expected that other complications, including ocular disorders, would also be similar.

Ocular complications of diabetes are the subject of many studies. Their type, incidence and pathomechanism have been largely known. Disorders can affect all anatomical structures in the visual system. The most common pathologies in patients with diabetes include: retinopathy, cataract, refraction and accommodation disorders, colour vision and contrast sensitivity disorders, changes in the protective apparatus and the ocular surface (recurrent inflammatory processes within the eyelid, weakening of the corneal sensation, morphological and functional changes in corneal epithelial and endothelial cells, decreased production of tears), paralysis of the oculomotor nerves (leading to double vision, paralytic strabismus and/ /or ptotic eyelid) and pupillary dysfunction.

Ocular complications of diabetes, especially diabetic retinopathy, are currently the leading cause of blindness among professionally active individuals in developed countries $[5,6]$.

Literature reports are available on the prevalence of retinopathy in prediabetic patients, but there are also data on the occurrence of other visual changes in people with IFG and/or IGT.

The purpose of our study was to evaluate ocular changes in patients with prediabetes.

\section{Material and methods}

The study included 60 patients (40 women, 20 men) with IFG and/or IGT aged 37-78 (mean age 58 years), treated in the Department of Internal Diseases, Diabetology and Endocrinology, Warsaw Medical University. The control group consisted of 30 volunteers (20 women, 10 men) aged 39-75 years (mean age 54 years) with normal fasting glucose and normal glucose level at $120 \mathrm{~min}$ post oral glucose load.

Prediabetes was diagnosed based on fasting blood glucose and glycaemia at 120 min of oral glucose tolerance test (OGTT) according to the following criteria: IFG - 100-125 mg/dL (5.6-6.9 mmol/L); IGT: glycaemia at $120 \mathrm{~min}$ of OGTT $-140-199 \mathrm{mg} / \mathrm{dL}(7.8-11 \mathrm{mmol} / \mathrm{L})$.
The study was approved by the Ethics Committee at WUM No. KB/190/2013. All patients gave informed written consent to participate in the study before performing diagnostic procedures.

In both analysed groups, a thorough history of internal and ophthalmic diseases was collected and a full physical examination was performed, including weight and height measurements, calculation of body mass index (BMI), waist and hips measurements, calculation of waist to hip ratio (WHR) and blood pressure measurement. Additionally, following biochemical parameters were determined: fasting blood glucose, OGTT, glycated haemoglobin $\left(\mathrm{HbA}_{1 \mathrm{c}}\right)$, fasting insulin, Homeostasis Model Assessment (HOMA) and lipidogram.

The ophthalmic examination included:

- assessment of near and distance visual acuity, without and with correction (using Snellen charts):

- assessment of the protective apparatus, the anterior segment of the eye and translucency of the lens in the slit-lamp;

- measurement of intraocular pressure by the aplanation method (Goldmann aplanation tonometer, Haag Streit, Switzerland);

— indirect ophthalmoscopy with Volk Digital Wide Field lens after pupillary dilation with $1 \%$ tropicamide;

- colour fundus photography (Retinal Camera TRC-NW7SF, MarkII, Topcon);

- optical coherence tomography (OCT) with SOCT Copernicus HR, Optopol Technology - evaluation of macular morphology and thickness and the vitreo-macular adhesion;

- assessment of colour vision with Ishihara pseudoisochromatic plates and Lanthony desaturated D-15 panel test (Richmond Products Inc.);

- contrast sensitivity test (Mars Perceptrix test).

In the prediabetic group, all tests were performed twice: during the first visit (V1) and then during the second visit after 9 months (V2).

On the first visit, following lifestyle modification recommendations were given to all patients with prediabetes: implement low-calorie diet (reduction of daily energy supply by $500 \mathrm{kcal}$ ) and increase daily physical activity to at least $20 \mathrm{~min}$ (minimum $140 \mathrm{~min}$ per week). Some patients, in addition to lifestyle modifications, were prescribed metformin.

The prediabetes group was compared with the control group for differences in the results of both ophthalmic and general medical examinations. Moreover, the results from two consecutive visits were compared (V1 vs. V2). Abnormal results of ophthalmic examinations were analysed for correlation with age, sex and results of general medical 
examination including hypertension, hypercholesterolaemia, ischaemic heart disease (IHD), smoking, overweight and obesity, $\mathrm{HbA}_{1 \mathrm{c}}$ levels and the use of anticoagulants.

Statistical analysis of the data was performed. The significance of the relationship between the categorical variables was assessed using $\chi^{2}$ test. U Mann-Whitney and Kruskal-Wallis tests were used to compare the continuous data. Statistica for Windows (version 5.0, StatSoft, Tulsa, OK, USA) was used for statistical calculations. Statistical significance was assumed at $p<0.05$.

\section{Results}

Of the 60 prediabetic patients included in the study, 32 (53.3\%) patients were diagnosed with IFG; $8(13.3 \%)$ with IGT and in $20(33.3 \%)$ patients both disorders were present (Fig. 1).

On the first visit, 10 patients with diagnosed prediabetes were prescribed 500 or 750 mg extendedrelease form of metformin.

The prediabetic group differed from the control group in terms of the prevalence of hypertension $(70 \%$ vs. $40 \%$; $p<0.05$ ) (Tab. 1) and a number of biochemical parameters (Tab. 2). Significant differences were observed in mean fasting glucose values (106.9 vs. $88.57 \mathrm{mg} / \mathrm{dL}, \mathrm{p}<0.05)$, OGTT (133.45 vs. $98.26 \mathrm{mg} / \mathrm{dL}$, $\mathrm{p}<0.05)$, fasting insulin (13.13 vs. $9.02 \mu \mathrm{lU} / \mathrm{mL}$; $\mathrm{p}<0.05)$, HOMA (3.30 vs. 1.94; $\mathrm{p}<0.05$ ) and $\mathrm{HbA}_{1 \mathrm{c}}$ (5.80 vs. $5.56 \% ; p<0.05)$.

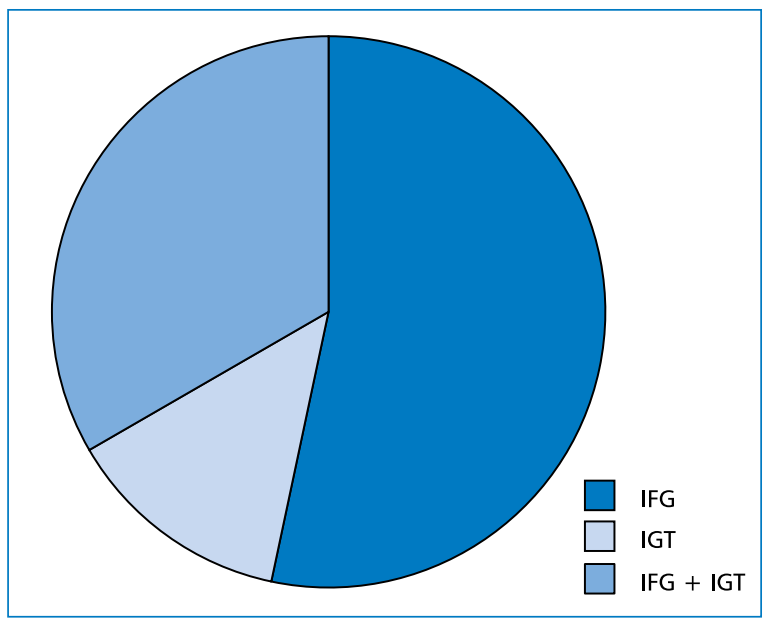

Figure 1. Types of prediabetic states; IFG - impaired fasting glucose; IGT — impaired glucose tolerance

Patients with prediabetes were significantly more likely to take antihypertensive medication (65\% vs. $36.7 \%$; $p<0.05$ ) compared with control subjects. There was no statistically significant difference between the groups in the frequency of the use of lipid-lowering drugs ( $35 \%$ vs. $20 \%$, NS) and anti-coagulants ( $25 \%$ vs. $20 \%$, NS) (Tab. 1).

There were also statistically significant differences between the prediabetes and control groups in BMI values (30.65 vs. $\left.27.47 \mathrm{~kg} / \mathrm{m}^{2} ; \mathrm{p}<0.05\right)$, waist circumfer-

Table 1. Comparison of medical history data between the prediabetic group and control group

\begin{tabular}{|c|c|c|c|}
\hline Parameter & Prediabetic group & Control group & $P$ value \\
\hline Number of patients $(\mathrm{N})$ & 60 & 30 & \\
\hline Age (years) & $58 \pm 9.0$ & $54 \pm 8.3$ & \\
\hline Hypertension & $42(70 \%)$ & $12(40 \%)$ & $<0.05$ \\
\hline Hypercholesterolaemia & $36(60 \%)$ & $18(60 \%)$ & NS \\
\hline Ischaemic heart disease & $8(13.33 \%)$ & $3(10 \%)$ & NS \\
\hline Myocardial infarction & $1(1.67 \%)$ & $0(0 \%)$ & NS \\
\hline PTCA & $2(3.33 \%)$ & $0(0 \%)$ & NS \\
\hline CABG & $0(0 \%)$ & $0(0 \%)$ & NS \\
\hline Stroke & $4(6.67 \%)$ & $1(3.33 \%)$ & NS \\
\hline Antihypertensive drugs & $39(65 \%)$ & $11(36.7 \%)$ & $<0.05$ \\
\hline Lipid-lowering drugs & $21(35 \%)$ & $6(20 \%)$ & NS \\
\hline Anti-coagulation drugs & $15(25 \%)$ & $6(20 \%)$ & NS \\
\hline Peripheral atherosclerosis & $1(1.67 \%)$ & $0(0 \%)$ & NS \\
\hline \multicolumn{4}{|l|}{ Smoking } \\
\hline Former & $32(53.33 \%)$ & $16(53.33 \%)$ & NS \\
\hline Current & $6(10 \%)$ & $6(20 \%)$ & NS \\
\hline \multicolumn{4}{|l|}{ Physical activity } \\
\hline Score from 0 to 5 & 3.06 & 2.66 & NS \\
\hline Mean number of hours per week & 8.3 & 8.7 & NS \\
\hline
\end{tabular}

CABG — coronary artery bypass grafting; NS — not significant; PTCA — percutaneous transluminal coronary angioplasty 
Table 2. Comparison of anthropometric parameters and laboratory data between the prediabetic group and control group

\begin{tabular}{|c|c|c|c|}
\hline Parameter & $\begin{array}{l}\text { Prediabetic group } \\
\text { mean } \pm \text { SD }\end{array}$ & $\begin{array}{l}\text { Control group } \\
\text { mean } \pm \text { SD }\end{array}$ & $P$ value \\
\hline Number of patients $(\mathrm{N})$ & 60 & 30 & \\
\hline Body mass index $\left[\mathrm{kg} / \mathrm{m}^{2}\right]$ & $30.65 \pm 4.77$ & $27.47 \pm 4.06$ & $<0.05$ \\
\hline Waist circumference in women $[\mathrm{cm}]$ & $95.9 \pm 9.02$ & $84.9 \pm 9.78$ & $<0.05$ \\
\hline Waist circumference in men [cm] & $105.3 \pm 14.58$ & $107.9 \pm 10.35$ & NS \\
\hline Waist to hip ratio & $0.9 \pm 0.09$ & $0.87 \pm 0.09$ & NS \\
\hline Systolic blood pressure [mm Hg] & $138.27 \pm 20.61$ & $125.59 \pm 12.4$ & $<0.05$ \\
\hline Diastolic blood pressure [mm Hg] & $81.79 \pm 10.27$ & $79.73 \pm 7.54$ & NS \\
\hline Fasting glucose [mg/dL] & $106.9 \pm 9.62$ & $88.57 \pm 5.92$ & $<0.05$ \\
\hline 2 h post-load glucose [mg/dL] & $133.45 \pm 41.08$ & $98.26 \pm 20.03$ & $<0.05$ \\
\hline $\mathrm{HbA}_{1 \mathrm{c}}[\%]$ & $5.80 \pm 0.38$ & $5.56 \pm 0.22$ & $<0.05$ \\
\hline Fasting insulinaemia $[\mu \mathrm{lU} / \mathrm{mL}]$ & $13.13 \pm 8.0$ & $9.02 \pm 4.46$ & $<0.05$ \\
\hline HOMA-IR & $3.30 \pm 2.2$ & $1.94 \pm 0.96$ & $<0.05$ \\
\hline Cholesterol [mg/dL] & $191.72 \pm 43.93$ & $211.67 \pm 34.71$ & $<0.05$ \\
\hline LDL [mg/dL] & $118.03 \pm 38.18$ & $138.07 \pm 31.18$ & $<0.05$ \\
\hline $\mathrm{HDL}[\mathrm{mg} / \mathrm{dL}]$ & $51.53 \pm 8.59$ & $50.70 \pm 9.95$ & NS \\
\hline Triglycerides [mg/dL] & $124.82 \pm 59.07$ & $115.23 \pm 52.51$ & NS \\
\hline
\end{tabular}

HDL — high density lipoprotein; HOMA — Homeostasis Model Assessment; LDL — low density lipoprotein; NS — non significant; SD — standard deviation

ence in women (95.9 vs. $84.9 \mathrm{~cm} ; \mathrm{p}<0.05)$ and systolic blood pressure (138.27 vs. $125.59 \mathrm{~mm} \mathrm{Hg}$; < 0.05). A detailed comparison of clinical parameters between the study groups is presented in Tables 1 and 2 .

In the ophthalmic examination, statistically significantly more cataracts were observed in prediabetic patients compared to controls (31.67\% vs. 6.67\%; $\mathrm{p}<0.05)$. In patients with prediabetes, corneal surface disorders such as punctate epitheliopathy, tear film instability and other tear film disorders $(21.67 \%$ vs. $3.33 \% ; p<0.05$ ) were also more frequently diagnosed, while subjective symptoms and diagnosis of dry eye syndrome (DES) had a comparable frequency in the study groups (Tab. 3).

Patients with prediabetes were significantly more likely (compared to control subjects) to have retinal artery narrowing ( $81.67 \%$ vs. $63.33 \% ; p<0.05)$ and hypertensive angiopathy ( $70 \%$ vs. $36.67 \%$; $p<0.05)$. In addition, a higher proportion of patients with prediabetes were diagnosed with more advanced stages of hypertensive angiopathy (grade II) (54.76\% vs. $27.27 \%$; $p<0.05$ ).

Complete or partial posterior vitreous detachment (PVD) $(76.67 \%$ vs. 55\%; $p<0.05)$ was more frequently revealed by OCT examination in prediabetic patients. The presence of epiretinal membrane (ERM) in the macula was observed in 8 eyes in prediabetic group, while in the control group it was present in 2 eyes (6.67\% vs. $3.33 \%$, respectively).

When compared the study groups, the prevalence of retinopathy was higher in patients with prediabetes.
It was diagnosed in 5 patients in prediabetic group and in 1 patient in control group ( $8.33 \%$ vs. $3.33 \%$; NS). In 3 patients with prediabetes, single microaneurysms or small intraretinal hemorrhages were observed, 1 patient was found to have a single focus of cotton wool, and 1 patient had symptoms of initial stage of maculopathy such as small hard exudates and microaneurysms in the macula.

Patients with prediabetes were also more likely to have colour vision disorders in the Lanthony desaturated D-15 panel test. Significant abnormalities in colour perception were observed in 5 subjects in the control group, but in none in the control group (8.33\% vs. $0 \%$, NS).

A detailed comparison of ophthalmic findings in prediabetic and control subjects is summarised in Table 3.

A multivariate analysis was performed of statistically significant differences in the results of ophthalmic screening in relation to additional parameters (age, gender, hypertension, lipid disorders, BMI, IHD, smoking) that may influence the incidence of ocular changes in patients with prediabetes. Patients with retinal artery narrowing were more likely to have hypertension (79.6\% vs. $27.3 \%$; $p$ < 0.05). These patients were also older compared to those without retinal artery narrowing (62.9 vs. 53.5 years; $p<0.05)$. Similar differences were observed in the hypertensive angiopathy group - higher proportion of patients with hypertension (97.6\% vs. $5.6 \%, p<0.05)$ and older age (63.8 vs. 55.1 
Table 3. Comparison of the results of ophthalmic examination between prediabetic group and control group

\begin{tabular}{|c|c|c|c|}
\hline Parameter & Prediabetic group & Control group & $P$ value \\
\hline Number of patients (N)/number of eyes (n) & $60 / 120$ & $30 / 60$ & \\
\hline \multicolumn{4}{|l|}{ Mean distance visual acuity } \\
\hline $\mathrm{RE}$ & 0.88 & 0.90 & NS \\
\hline LE & 0.87 & 0.91 & NS \\
\hline \multicolumn{4}{|l|}{ Mean intraocular pressure $[\mathrm{mm} \mathrm{Hg}]$} \\
\hline $\mathrm{RE}$ & 15.10 & 13.83 & NS \\
\hline LE & 15.07 & 14.07 & NS \\
\hline \multicolumn{4}{|l|}{ Disorders of corneal surface and lids; N (\%) } \\
\hline Conjunctival irritation & $8(13.33 \%)$ & $4(13.33 \%)$ & NS \\
\hline Superficial keratopathy & $13(21.67 \%)$ & $1(3.33 \%)$ & $<0.05$ \\
\hline Blepharitis & $1(1.67 \%)$ & $1(3.33 \%)$ & NS \\
\hline Dry eye; N (\%) & $20(33.33 \%)$ & $10(33.33 \%)$ & NS \\
\hline Cataract; N (\%) & $19(31.67 \%)$ & $2(6.67 \%)$ & $<0.05$ \\
\hline Retinopathy; N (\%) & $5(8.33 \%)$ & $1(3.33 \%)$ & NS \\
\hline Retinal artery narrowing; N (\%) & $49(81.67 \%)$ & $19(63.33 \%)$ & $<0.05$ \\
\hline Hypertensive angiopathy; N (\%) & $42(70 \%)$ & $11(36.67 \%)$ & \\
\hline Stage I & $12(28.57 \%)$ & $6(54.55 \%)$ & $<0.05$ \\
\hline Stage $1 / I I$ & $7(16.67 \%)$ & $2(18.18 \%)$ & \\
\hline Stage II & $23(54.76 \%)$ & $3(27.27 \%)$ & \\
\hline \multicolumn{4}{|l|}{ Colour vision disturbances; N (\%) } \\
\hline Lanthony D-15 test & $5(8.33 \%)$ & $0(0 \%)$ & NS \\
\hline Ishihara test & $2(3.33 \%)$ & $0(0 \%)$ & NS \\
\hline Impaired contrast sensitivity; N (\%) & $1(1.67 \%)$ & $1(3.33 \%)$ & NS \\
\hline Posterior vitreous detachment; $\mathrm{n}(\%)$ & $92(76.67 \%)$ & $33(55 \%)$ & $<0.05$ \\
\hline \multicolumn{4}{|l|}{ Mean central retinal thickness $[\mu \mathrm{m}]$} \\
\hline RE & 193.15 & 193.27 & NS \\
\hline LE & 195.02 & 191.27 & NS \\
\hline \multicolumn{4}{|l|}{ Macular changes; n (\%) } \\
\hline Epiretinal membrane & $8(6.67 \%)$ & $2(3.33 \%)$ & NS \\
\hline Degenerative changes (RPE disorders) & $31(25.83 \%)$ & $15(25 \%)$ & NS \\
\hline Vitreo-retinal traction & $3(2.5 \%)$ & $1(1.67 \%)$ & NS \\
\hline Macular hole & $1(0.83 \%)$ & $0(0 \%)$ & NS \\
\hline
\end{tabular}

NS — non significant; LE — left eye; RE — right eye; RPE — retinal pigment epithelium

years). The prevalence of PVD was influenced by obesity and overweight (BMI $\geq 25 \mathrm{~kg} / \mathrm{m}^{2} ; 95.8 \%$ vs. $66.7 \%$; $\mathrm{p}<0.05)$. Patients with cataract were predominantly female (89.5\% vs. $56.1 \% ; p<0.05)$ and were older (68.8 vs. 57.7 years; $p<0.05)$ compared with those without cataract. Patient with or without superficial corneal keratopathy differed only in gender - women were more frequently affected $(92.3 \%$ vs. $59.6 \%$; $p<0.05)$. There were no statistically significant differences in the other parameters analysed.

Additionally, a multivariate analysis of ophthalmic disorders was performed, which showed a trend toward frequent occurrence in people with prediabetes (but not statistically significant). The analysis included the same, above-described parameters that may influ- ence the incidence of ocular changes. Patients with ERM were older (69.6 vs. 60.3 years; $p<0.05$ ), with a significant predominance of women (100\% vs. $63 \%$; $\mathrm{p}<0.05)$. These patients were also more likely to have IHD $(66.7 \%$ vs. $7.4 \%, p<0.05)$. Patients with acquired abnormalities of colour vision were statistically significantly older than patients without these disorders (71.7 vs. 60.3 years; $p<0.05)$. There were no statistically significant differences in the other parameters analysed.

The results of the ophthalmic and general medical examinations in prediabetic patients obtained during the first visit were compared with the results of the examinations performed during the second visit that took place around 9 months later $(8.6$ months on average). During the second visit, 55 patients with 
Table 4. Comparison of the results of general medical examination and laboratory tests performed at baseline (Visit 1) and after 9 months (Visit 2) in patients with prediabetes

\begin{tabular}{lccc}
\hline Parameter & Visit 1 & Visit 2 & P value \\
& mean \pm SD & mean \pm SD & \\
\hline Number of patients $(\mathrm{N})$ & 60 & 35 & NS \\
Body mass index $\left[\mathrm{kg} / \mathrm{m}^{2}\right]$ & $30.65 \pm 4.77$ & $95.6 \pm 9.46$ & NS \\
Waist circumference in women $[\mathrm{cm}]$ & $95.9 \pm 9.02$ & $105.6 \pm 15.07$ & NS \\
Waist circumference in men $[\mathrm{cm}]$ & $105.3 \pm 14.58$ & $0.89 \pm 0.09$ & NS \\
Waist to hip ratio & $0.9 \pm 0.09$ & $134.82 \pm 20.20$ & NS \\
Systolic blood pressure $[\mathrm{mm} \mathrm{Hg]}$ & $138.27 \pm 20.61$ & $80.14 \pm 10.42$ & NS \\
Diastolic blood pressure $[\mathrm{mm} \mathrm{Hg]}$ & $81.79 \pm 10.27$ & $104.08 \pm 8.79$ & $<0.05$ \\
Fasting glucose $[\mathrm{mg} / \mathrm{dL}]$ & $106.9 \pm 9.62$ & $130.74 \pm 42.89$ & NS \\
2 h post-load glucose $[\mathrm{mg} / \mathrm{dL}]$ & $133.45 \pm 41.08$ & $5.99 \pm 0.45$ & $<0.05$ \\
HbA ${ }_{1 \mathrm{c}}[\%]$ & $5.80 \pm 0.38$ & $12.01 \pm 7.21$ & NS \\
Fasting insulinaemia $[\mu \mathrm{lU} / \mathrm{mL}]$ & $13.13 \pm 8.0$ & $3.25 \pm 2.06$ & NS \\
HOMA-IR & $3.30 \pm 2.2$ & $186.24 \pm 41.41$ & NS \\
Cholesterol $[\mathrm{mg} / \mathrm{dL}]$ & $191.72 \pm 43.93$ & $112.36 \pm 34.64$ & NS \\
LDL $[\mathrm{mg} / \mathrm{dL}]$ & $118.03 \pm 38.18$ & $50.91 \pm 9.19$ & NS \\
HDL [mg/dL] & $51.53 \pm 8.59$ & $115.53 \pm 48.91$ & NS \\
Triglycerides $[\mathrm{mg} / \mathrm{dL}]$ & $124.82 \pm 59.07$ & & \\
\hline
\end{tabular}

HDL — high density lipoprotein; HOMA — Homeostasis Model Assessment; LDL — low density lipoprotein; NS — non significant; SD — standard deviation

prediabetes were examined (5 patients did not report for the next visit). When comparing data obtained during V1 and V2, there were statistically significant differences in fasting glucose (106.9 vs. $104.1 \mathrm{mg} / \mathrm{dL}$; $\mathrm{p}<0.05)$ and $\mathrm{HbA}_{1 \mathrm{c}}(5.80 \%$ vs. $5.99 \%$; $\mathrm{p}<0.05)$. Nine months after the first visit, the proportion of patients with retinopathy was $12.73 \%$, indicating a trend toward an increase in the incidence of this complication. There were no significant differences in other ocular changes between V2 and V1. A detailed comparison of the results obtained during the two visits is shown in Table 4 (general medical examination data) and Table 5 (ophthalmic examination data).

The results of ophthalmic examinations in patients with prediabetes were analysed for correlation with relevant clinical parameters. When compared patients with coexisting hypertension to normotensive patients, statistically significant differences were found only in the incidence of retinal artery narrowing $(92.9 \%$ vs. $55.6 \% ; p<0.05)$ and hypertensive angiopathy $(97.6 \%$ vs. $0 \% ; p<0.05)$. There were no statistically significant differences in the incidence of ocular changes with respect to lipid disorders, smoking, overweight and obesity, $\mathrm{HbA}_{1 \mathrm{c}}$ and anticoagulation treatment.

\section{Discussion}

The main pathophysiological factors of the prediabetic state are impaired insulin secretion and insulin resistance. This is reflected in the results of our study.
In the prediabetic group, we found higher HOMA $(3.30 \pm 2.2)$, which is indicative of insulin resistance, than in the control group. In addition, patients with prediabetes had a higher BMI $\left(30.65 \pm 4.77 \mathrm{~kg} / \mathrm{m}^{2}\right)$, reflecting the prevalence of obesity and overweight in this population. Abdominal obesity was observed both in women and in men in the prediabetic group. Obesity and overweight (BMI $\geq 25 \mathrm{~kg} / \mathrm{m}^{2}$ ) are associated with insulin resistance and are considered to be the main risk factors for prediabetes, as confirmed by the results of our study.

The majority of patients with prediabetes (70\%) had concomitant hypertension, which was statistically significantly different from those in the control group ( $40 \%$ of hypertensive subjects). The presence of hypertension in the study group was closely correlated with the diagnosis of retinal artery narrowing and hypertensive angiopathy. Elderly was an additional factor influencing these disorders.

Most of patients with prediabetes and hypertension were diagnosed with stage II hypertensive angiopathy (54.8\%) and the changes were more advanced than in the control group in which we most frequently observed stage I angiopathy. This may indicate an additional effect of prediabetes on the development of retinal blood vessel lesions. It cannot be ruled out that more advanced hypertension has contributed to the onset of prediabetes. However, there is undoubtedly a close relationship between hypertension and glucose 
Table 5. Comparison of the results of ophthalmic examinations performed during Visit 1 and Visit 2 in patients with prediabetes

\begin{tabular}{|c|c|c|c|}
\hline Parameter & Visit 1 & Visit 2 & $P$ value \\
\hline Number of patients (N)/number of eyes (n) & $60 / 120$ & $55 / 110$ & \\
\hline \multicolumn{4}{|l|}{ Mean distance visual acuity } \\
\hline RE & 0.88 & 0.89 & NS \\
\hline LE & 0.87 & 0.88 & NS \\
\hline \multicolumn{4}{|l|}{ Mean intraocular pressure [mm Hg] } \\
\hline $\mathrm{RE}$ & 15.10 & 14.49 & NS \\
\hline LE & 15.07 & 14.49 & NS \\
\hline \multicolumn{4}{|l|}{ Disorders of corneal surface and lids; N (\%) } \\
\hline Conjunctival irritation & $8(13.33 \%)$ & $3(5.45 \%)$ & NS \\
\hline Superficial keratopathy & $13(21.67 \%)$ & $13(23.64 \%)$ & NS \\
\hline Blepharitis & $1(1.67 \%)$ & $1(1.82 \%)$ & NS \\
\hline Dry eye; N (\%) & $20(33.33 \%)$ & $20(36.36 \%)$ & NS \\
\hline Cataract; N (\%) & $19(31.67 \%)$ & $17(30.91 \%)$ & NS \\
\hline Retinopathy; N (\%) & $5(8.33 \%)$ & $7(12.73 \%)$ & NS \\
\hline \multicolumn{4}{|l|}{ Colour vision disturbances; N (\%) } \\
\hline Lanthony D-15 test & $5(8.33 \%)$ & $6(10.91 \%)$ & NS \\
\hline Ishihara test & $2(3.33 \%)$ & $2(3.64 \%)$ & NS \\
\hline Impaired contrast sensitivity; N (\%) & $1(1.67 \%)$ & $1(1.82 \%)$ & NS \\
\hline Posterior vitreous detachment; $\mathrm{n}(\%)$ & $92(76.67 \%)$ & $84(76.36 \%)$ & NS \\
\hline \multicolumn{4}{|l|}{ Mean central retinal thickness $[\mu \mathrm{m}]$} \\
\hline $\mathrm{RE}$ & 193.15 & 194.26 & NS \\
\hline LE & 195.02 & 196.13 & NS \\
\hline \multicolumn{4}{|l|}{ Macular changes; n (\%) } \\
\hline Epiretinal membrane & $8(6.67 \%)$ & $8(7.27 \%)$ & NS \\
\hline Degenerative changes (RPE disorders) & $31(25.83 \%)$ & $28(25.45 \%)$ & NS \\
\hline Vitreo-retinal traction & $3(2.5 \%)$ & $2(1.82 \%)$ & NS \\
\hline Macular hole & $1(0.83 \%)$ & $1(1.82 \%)$ & NS \\
\hline
\end{tabular}

NS — non significant; LE — left eye; RE — right eye; RPE — retinal pigment epithelium

tolerance disorders, and this correlation was confirmed in our study.

Many data indicate that prediabetes is associated with the risk of diabetic complications, including ocular changes. Most studies in the world literature concern retinopathy that is the most serious ocular complication of diabetes and the leading cause of vision impairment and blindness in diabetic patients. Its frequency in people with IFG and/or IGT is estimated in the previous analysis at 7.9-12\% [7-9]. In our study, the proportion of patients with retinopathy was $8.33 \%$, which is comparable to the results of other researchers. After 9 months, the prevalence of retinopathy in our patients increased to $12.73 \%$. In our study, we mainly recognised symptoms of mild non-proliferative retinopathy, which is consistent with observations of other authors. Based on the medical history, ophthalmic examination and laboratory tests, we have excluded the local causes of retinopathy in the patients studied, including retinal and choroidal inflammatory processes, retinal vasculitis, vascular anomalies, or retinal vein thrombosis. Changes in the nature of retinopathy may also be associated with non-diabetic systemic disorders such as hypertension, especially if poorly controlled, high BMI, coronary heart disease, and anticoagulation treatment. Retinopathy may also be a symptom of retinal ischaemia against the background of carotid stenosis. Based on Doppler ultrasound examination and medical history data we have excluded ischaemic aetiology in patients who have been diagnosed with retinopathy. We have not found any haemodynamically significant carotid flow disturbances in these patients.

World literature indicates the co-existence of additional risk factors of retinopathy in patients with prediabetes. The analyses concern mainly hypertension, obesity and cardiovascular diseases. The study performed in Chinese population indicates a statistically significant association between the prevalence of IGT in retinopathy 
patients and hypertension and obesity [10]. The Swedish study also showed a significant association between the occurrence of retinopathy and blood pressure values and higher BMI in patients with IFG [9]. Based on multivariate analysis, we did not find in prediabetic patients any relationship between the prevalence of retinopathy and hypertension and elevated BMI, or age, gender, lipid disorders, IHD, and cigarette smoking.

One of the most common complications of diabetes is cataract, which was diagnosed in $31.67 \%$ of patients in the prediabetes group in our study. It was statistically significantly more common in the prediabetic group than in the control group (6.67\%). Hyperglycaemia leads to lens opacity due to increased osmotic pressure inside the lens and increased hydration. It can be assumed that the fluctuations of glycaemia, which occur at the stage of prediabetes, contribute to the faster development of lens opacity. We diagnosed cataract even in patients with lens opacity at a very early stage, often with still good visual acuity, which may have resulted in a high prevalence of cataract in our study. Patients with prediabetes who were diagnosed with cataract were older compared to those without cataract ( 68.8 vs. 57.7 years; $p<0.05$ ). This result is in line with expectations as age is one of the main risk factors of lens opacification.

Despite considerable differences in prevalence of cataract in the prediabetic and control groups, no significant differences were observed between the groups in the average visual acuity with the best correction, for both near and distant vision. This may indicate a low grade lens opacity in patients with prediabetes. In most cases, we diagnosed initial cataract that did not significantly affect vision, but structural changes in lenses have already occurred.

Corneal epithelial surface lesions such as punctate epitheliopathy, tear film instability and other tear film disorders were more common in patients with prediabetes than in control subjects. In turn, subjective symptoms of DES were present in both groups with a comparable frequency. In diabetic patients, the symptoms of DES are often seen in the physical examination due to disturbances in morphology and function of corneal epithelium and reduced production of tears. Sometimes, these changes are not accompanied by subjective symptoms, which is due to impaired corneal sensitivity in people with diabetes [5]. Our results suggest that these disorders develop already at the prediabetic stage.

Optical coherent tomography is currently the primary examination performed in patients with diabetes to diagnose and monitor macular changes and to evaluate vitreo-retinal disorders. In available literature, there are no studies evaluating these structures in OCT in prediabetic patients. Thanks to the OCT, we have been able to assess the macula and the vitreoretinal interface in all our patients. In patients with prediabetes, we found a higher prevalence of PVD than in the control group. This difference was statistically significant. The prevalence of PVD is mainly affected by the age of the patients, but there are also other known risk factors including: greater eye length and myopia, aphakia, inflammatory diseases, eye traumas, and ocular surgery [11]. World literature provides data indicating a higher prevalence of PVD in patients with type 2 diabetes compared to non-diabetic patients [ 12 , 13]. The results of our study indicate that also prediabetes should be considered as a factor favouring the posterior vitreous detachment. Multivariate analysis showed that obesity and overweight (BMI $\geq 25 \mathrm{~kg} / \mathrm{m}^{2}$ ) were additional factors influencing the prevalence of PVD in our prediabetic patients. These disorders are closely related to IGT.

Besides the typical symptoms of diabetic maculopathy, vitreoretinal disorders are also observed in OCT, such as ERM [14]. Epiretinal membranes are observed with diabetic retinopathy even in $25-30 \%$ of patients [15]. In our study, ERM was detected in $6.67 \%$ of the eyes in the prediabetic group and in $3.33 \%$ of eyes (NS) in the control group. Prediabetic patients with ERM were older than those without ERM. This trend is also observed in the general population. It should be noted that the frequency of ERM in patients with IFG and/or IGT and coexisting IHD is higher compared with those without IHD, which is probably related to older age of patients in this group.

Colour vision disturbances assessed by the Lanthony D-15 test were observed in $8.33 \%$ of patients with prediabetes in our study, but not in the control group. This test mainly serves to diagnose acquired disorders (blue-yellow axis); therefore, it can be assumed that the disorders in our patients were acquired in nature. There were no abnormalities in the results of Ishihara test detecting the red-green axis disorders. Acquired colour vision disorders are considered to be an early and sensitive indicator of various neurodegenerative and neurotoxic diseases. They are often found in patients with diabetes, both complicated and uncomplicated by retinopathy $[5,16-18]$.

The results of studies available in the world literature suggest that prediabetes may be a risk factor of both colour vision disturbances and impaired contrast sensitivity; although, the results of previous studies are not clear $[18,19]$. These changes are early visual dysfunction that may be present before the onset of other symptoms of retinal damage and indicate the initial stage of the disease. In prediabetic patients, we 
observed a tendency to more frequent occurrences of early acquired colour vision disturbances. The results of our study may indicate the risk of their development at an early stage of glycaemic disorders. However, it should be borne in mind that people with diagnosed colour vision disorders were older than the rest of the patients.

One of the risk factors of the development of complications is the duration of the glucose metabolism disturbances. In our study, we compared the results obtained in prediabetic patients on initial visit with the results obtained after 9 months. We have not found any statistically significant differences in the prevalence of ocular changes, but it is worth noting the trend toward an increase in the incidence of retinopathy, as mentioned earlier. However, significant changes were observed in $\mathrm{HbA}_{1 \mathrm{c}}$ levels (increase from $5.8 \%$ to $5.99 \%$ ), which may indicate the progression of metabolic disorders. On the second visit, the mean fasting glucose level was lower, which may result from increased patient awareness of the nature of the disorder and better preparedness for the next visit. The increase in $\mathrm{HbA}_{1 \mathrm{c}}$ was probably associated with postprandial hyperglycaemia, higher than in the first examination.

The limitation of our study is the relatively short time of observation. Significant changes in visual acuity, its prevalence and severity can be expected after a longer period of time. However, despite a fairly short interval between two successive patient assessments, a tendency can be noted for progression of some metabolic disorders and ocular changes. Long-term evaluation of ocular changes in patients with prediabetes requires further research.

\section{Conclusions}

In patients with prediabetes, ocular changes are more common than in those without glucose metabolism disturbances. Various structures of the eye can be affected; possible ocular changes include: cataract, corneal surface disorders and PVD. Prediabetic patients are also more likely to develop other ocular disorders, especially retinopathy.

The results of our study indicate that prediabetes is an independent risk factor of many of these complications; although, many patients with prediabetes have other features of metabolic syndrome (insulin resistance).

In conclusion, it should be noted that the regular ophthalmic monitoring seems to be essential at the stage of prediabetes in order to detect ocular abnormalities and identify individuals at risk of other diabetic complications.

\section{REFERENCES}

1. Piątkiewicz P. Cukrzyca. Aspekty prawne i społeczne. Via Medica, Gdańsk 2016: 4-8.

2. Brannick B, Wynn A, Dagogo-Jack S. Prediabetes as a toxic environment for the initiation of microvascular and macrovascular complications. Exp Biol Med (Maywood). 2016; 241(12): 1323-1331, doi: 10.1177/1535370216654227, indexed in Pubmed: 27302176.

3. Tabák AG, Herder C, Rathmann W, et al. Prediabetes: a highrisk state for diabetes development. Lancet. 2012; 379(9833): 2279-2290, doi: 10.1016/S0140-6736(12)60283-9, indexed in Pubmed: 22683128.

4. Huang Y, Cai X, Mai W, et al. Association between prediabetes and risk of cardiovascular disease and all cause mortality: systematic review and meta-analysis. BMJ. 2016; 355: i5953, doi: 10.1136/ bmj.i5953, indexed in Pubmed: 27881363.

5. Wilczyński M, Borucka A. Powikłania okulistyczne cukrzycy. Okulistyka. Okulistyka. 2008; 3(3): 1-27.

6. Mirkiewicz-Sieradzka B. Cukrzycowa choroba oczu. In: Sieradzki J. ed. Cukrzyca. Via Medica, Gdańsk 2015: 569-596.

7. Lamparter J, Raum P, Pfeiffer N, et al. Prevalence and associations of diabetic retinopathy in a large cohort of prediabetic subjects: the Gutenberg Health Study. J Diabetes Complications. 2014; 28(4): 482-487, doi: 10.1016/j.jdiacomp.2014.02.008, indexed in Pubmed: 24630763.

8. Diabetes Prevention Program Research Group. The prevalence of retinopathy in impaired glucose tolerance and recent-onset diabetes in the Diabetes Prevention Program. Diabet Med. 2007; 24(2): 137-144, doi: 10.1111/j.1464-5491.2007.02043.x, indexed in Pubmed: 17257275.

9. Tyrberg M, Melander A, Lövestam-Adrian M, et al. Retinopathy in subjects with impaired fasting glucose: the NANSY-Eye baseline report. Diabetes Obes Metab. 2008; 10(8): 646-651, doi: 10.1111/j.1463-1326.2007.00759.x, indexed in Pubmed: 17645554.

10. Pang $C$, Jia $L$, Jiang $S$, et al. Determination of diabetic retinopathy prevalence and associated risk factors in Chinese diabetic and pre-diabetic subjects: Shanghai diabetic complications study. Diabetes Metab Res Rev. 2012; 28(3): 276-283, doi: 10.1002/ /dmrr.1307, indexed in Pubmed: 22139892.

11. Regillo C, Chang TS, Johnson MW. Basic and Clinical Science Course. Czéść 12 - Siatkówka i ciało szkliste. Wydanie I polskie pod red. Krystyny Pecold. Elsevier Urban \& Partner, Wrocław 2007: 280-282.

12. Liu $\mathrm{L}$, Yue $\mathrm{S}, \mathrm{Wu} \mathrm{J}$, et al. The Prevalence and Distribution of Vitreoretinal Interface Abnormalities among Urban Community Population in China. J Ophthalmol. 2015; 2015: 742686, doi: 10.1155/2015/742686, indexed in Pubmed: 26759726.

13. Gella L, Raman R, Pal SS, et al. Incidence, Progression, and Associated Risk Factors of Posterior Vitreous Detachment in Type 2 Diabetes Mellitus: Sankara Nethralaya Diabetic Retinopathy Epidemiology and Molecular Genetic Study. Semin Ophthalmol. 2015; 19: 1-7.

14. Aung KZ, Makeyeva G, Adams MK, et al. The prevalence and risk factors of epiretinal membranes: the Melbourne Collaborative Cohort Study. Retina. 2013; 33(5): 1026-1034, doi: 10.1097/ IIAE.0b013e3182733f25, indexed in Pubmed: 23400080.

15. Wylęgała E, Nowińska A, Teper S. Optyczna koherentna tomografia. Tom II. Bedeker Okulistyczny. Górnicki Wydawnictwo Medyczne, Wrocław 2011: 81-85

16. Stopyra W. Widzenie barw. Okulistyka - Program Edukacyjny Kompendium Okulistyki. 2012; 19(3): 1-18.

17. Malukiewicz G, Lesiewska-Junk H, Kaźmierczak K. Zaburzenia widzenia barwnego i wrażliwości na kontrast u chorych z cukrzycą typu II bez cech retinopatii. Klin Oczna. 2009; 111: 221-223.

18. Shoji T, Sakurai $Y$, Sato $H$, et al. Do type 2 diabetes patients without diabetic retinopathy or subjects with impaired fasting glucose have impaired colour vision? The Okubo Color Study Report. Diabet Med. 2011; 28(7): 865-871, doi: 10.1111/j.14645491.2011.03290.x indexed in Pubmed: 21418090.

19. Karadeniz S, Kir N, Yilmaz MT, et al. Alteration of visual function in impaired glucose tolerance. Eur J Ophthalmol. 1996; 6(1): 59-62, indexed in Pubmed: 8744852. 